American Journal of Pharmaceutical Education 2019; 83 (2) Article 6519.

\title{
RESEARCH
}

\section{Implementation of a Renal Replacement Therapy Simulation to Strengthen Essential Pharmacist Skills}

\author{
Aimon C. Miranda, PharmD, ${ }^{a}$ Radha V. Patel, PharmD, MPH, ${ }^{a}$ Shyam R. Gelot, PharmD, \\ Rowshan Chowdhury, PharmD, ${ }^{a}$ Erini S. Serag-Bolos, PharmD ${ }^{a}$ \\ ${ }^{a}$ College of Pharmacy, University of South Florida, Tampa, Florida \\ ${ }^{\mathrm{b}}$ Department of Pharmacy, Lee Memorial Health System, Fort Myers, Florida \\ Submitted May 15, 2017; accepted August 8, 2017; published March 2019.
}

\begin{abstract}
Objective. To assess third-year pharmacy students' knowledge and application of renal pharmacotherapy using a renal replacement therapy (RRT) simulation.

Methods. A simulation was developed that involved three stations related to RRT: peritoneal dialysis, continuous renal replacement therapy (CRRT), and hemodialysis. Stations involved demonstration of each modality, literature searches for drug information questions related to renal dosing with written recommendations, and utilization of an electronic medical record (EMR) to develop a verbal Situation, Background, Assessment, Recommendation (SBAR) for a patient with chronic kidney disease (CKD). Pre- and post-simulation assessments regarding therapeutic knowledge of RRT was used.

Results. All 174 students completed the pre- and post-simulation assessments over the course of two years. Student performance indicated significant improvement in overall knowledge based on the assessments with significant overall differences in questions relating to indications for RRT, type of RRT indicated for hemodynamic instability, and agents used to maintain circuit patency. Overall interclass differences were also identified at baseline and specifically for the questions regarding indications for RRT and agents used to maintain circuit patency. Both classes showed significant improvement in overall knowledge based on the post-simulation assessments. Debrief sessions and course evaluations indicated student satisfaction with the simulation experience. Students reported that the experience met the simulation objectives.

Conclusion. Participation in an RRT simulation allowed pharmacy students to apply knowledge and skills learned didactically related to renal pharmacotherapy.
\end{abstract}

Keywords: simulation, clinical competence, electronic medical record, renal replacement, renal pharmacotherapy

\section{INTRODUCTION}

The National Kidney Foundation has established clinical practice guidelines for the evaluation and management of patients with kidney disease. ${ }^{1,2}$ Despite this, renal pharmacotherapy concepts are challenging to teach and master in the Doctor of Pharmacy (PharmD) curriculum and across clinical practice. Possible reasons for this include but are not limited to varying methods of calculating renal clearance and variations in patient-specific parameters that may affect renal clearance. In addition, the approaches used in treating patients with acute versus chronic kidney disease (CKD) and renal replacement therapy (RRT) further adds to the complexity of drug dosing and administration. As a result, both students and pharmacists may find it difficult to master the concept

Corresponding Author: Radha V. Patel. Tel: 813-974-8604. E-mail: rvanmali85@gmail.com of appropriate drug dosing for patients with renal dysfunction.

The Accreditation Council for Pharmacy Education (ACPE) Standards 2016 and the Center for Advancement of Pharmacy Education (CAPE) Educational Outcomes 2013 emphasize the importance of foundational knowledge, patient-centered care for special populations, literature evaluation, and problem-solving within the PharmD curriculum, which can be mapped to approaches used to teach renal pharmacotherapy. ${ }^{3,4}$ Similarly, the American Society of Health-System Pharmacists also identifies medication dosing in renal dysfunction as one of the 20 pharmaceutical care competencies for pharmacists. ${ }^{5}$ For these reasons, and because renal function is often affected by various comorbidities, the approach to renal pharmacotherapy instruction must be considered to accommodate various learner levels and adequately integrate multiple concepts in the didactic curriculum. 


\section{American Journal of Pharmaceutical Education 2019; 83 (2) Article 6519.}

The use of simulation to enhance application of renal concepts has not been described in the pharmacy literature, but has been well-described in the nursing and medical education literature. ${ }^{6-8}$ In addition, pharmacy simulation has varied in the literature in terms of simulation methods, learner level, and assessment methods. ${ }^{9-12}$ Low- and high-fidelity simulation activities provide students an opportunity to apply their knowledge and practice their problem-solving and communication skills in a protected environment. The pedagogical approaches in the pharmacy education literature related to the application of renal concepts are limited to case-based problem learning activities, a flipped classroom approach within a pharmacotherapy course, or experiential education. ${ }^{13-17}$ Pierce and colleagues described improved student performance and enhanced perceptions from a flipped classroom model followed by patient cases to teach a renal pharmacotherapy module. ${ }^{14}$ Strohfeld and colleagues showed that case studies related to renal therapeutics followed by written pharmaceutical care plans achieved desired learning outcomes. ${ }^{16}$ Lastly, Benedict and colleagues described the use of an online patient case software following lectures related to critically ill patients with CKD and found improved knowledge depicted by pre- and post-activity assessments and test scores. ${ }^{17}$

The RRT simulation activity created at the University of South Florida (USF) College of Pharmacy was intended to integrate and assess retention of foundational concepts learned in the pharmacotherapeutics course regarding CKD and RRT and provide students with the opportunity to further enhance their drug information and communication skills. The objective of this study was to assess students' knowledge before and after the RRT simulation in two different cohorts of third year pharmacy (P3) students.

\section{METHODS}

An RRT simulation-based learning activity was developed alongside the traditional teaching methods of the pharmacotherapeutics renal module in the second (P2) year curriculum at the University of South Florida College of Pharmacy. Renal lecture topics included renal medicinal chemistry and pharmacology, acid and base disorders, fluids and electrolytes, acute renal failure (ARF), and chronic kidney disease. Total contact time, including case discussions, for the renal module was 10 hours in the fall semester. Other topics related to renal pharmacotherapy, such as drug dosing in renal insufficiency and drug dosing in dialysis, were addressed in the clinical pharmacokinetics and pharmacodynamics course for three lecture hours in the $\mathrm{P} 2$ spring semester. All lectures were taught or overseen by the same two core faculty members to ensure continuity between the content.

The RRT simulation then occurred the following fall semester of the P3 year in the pharmaceutical skills course, which is intended to allow for vertical and horizontal integration of topics through active learning. This simulation allowed for higher levels of Bloom's taxonomy through application of pharmacotherapeutic knowledge and delved into more advanced clinical topics, including analysis and evaluation of scenarios involving RRT, associated clinical considerations, and proper dosage adjustments. ${ }^{18}$ Additionally, the simulation emphasized drug information and literature evaluation skills, pharmaceutical calculations, and verbal patient presentation skills.

Planning of the simulation occurred over three months and was completed by three core faculty members. The faculty met each week for two hours to discuss simulation logistics, assessment measures, and knowledge content. A clinical pharmacy specialist and critical care dialysis nurse developed and gave a lecture prior to the simulation activity. They also worked with the core faculty members to ensure that the content of the simulation was practical and clinically applicable. Faculty met with the personnel at the simulation center one month before the activity to run through simulation logistics.

The station schedule was staggered, and three groups began the simulation each round but worked independently. Students could use their iPads for access to electronic medical record (EMRs) that contained the simulation patient's charts and access to drug information resources. EMRs used in the simulation included Epic (Epic Systems Corporation, Verona, WI) and Allscripts (Allscripts Healthcare Solutions, Inc., Chicago, IL) for the inpatient and outpatient settings, respectively. Patients' charts were developed through collaboration with USF Health Informational System (IS).

A week prior to the simulation, students received a 2hour didactic component covering pharmacist-related issues with continuous renal replacement therapy (CRRT), peritoneal dialysis (PD), and hemodialysis (HD). A clinical pharmacy specialist and dialysis nurse from a local public hospital prepared and taught the material. Three core faculty members reviewed the lecture materials prior to the live presentation to ensure that specific topics were addressed. Specific teaching points were emphasized at each simulation station. Students were instructed to review their materials from the pharmacotherapeutics renal module prior to participating in the simulation.

The simulation was held at the Center for Advanced Medical Learning and Simulation (CAMLS), a state-ofthe art health care simulation and training center with 


\section{American Journal of Pharmaceutical Education 2019; 83 (2) Article 6519.}

high-fidelity manikins and rooms that resemble inpatient settings (eg, emergency room and critical care units), outpatient settings (eg, ambulatory care clinics), and inpatient and outpatient pharmacy settings. On the day of the simulation, students attended a 20 -minute orientation session prior to the start of the activity to complete the pre-assessment, review expectations, schedules, station layout, and answer any questions. Students worked in groups of five to six students, which were randomly assigned by the Office of Student Affairs at the start of each academic year. Every group had a designated group leader for each station and students were instructed to rotate roles between stations. Each of the three stations was 20 minutes in duration. At the end of the simulation, there was a 20-minute debriefing session for students to complete the post-simulation assessment and reflect on the simulation. Upon completion of the assessment, faculty reiterated key teaching points and students provided verbal feedback to the faculty regarding the simulation.

The first station focused on concepts related to peritoneal dialysis. Three manikins depicting a patient on peritoneal dialysis were set up. A clinical pharmacist served as a facilitator and discussed how peritoneal dialysis works, infection risks and drug administration during dialysis. Students then received a corresponding scenario of a pharmacy consult to dose peritoneal vancomycin for a patient who had developed peritonitis. Workstations on wheels were also set up next to each manikin and students were required to verify a peritoneal dialysis order set using Epic.

The second station involved a discussion of how CRRT works, including demonstration of a CRRT bag and mechanical set-up, overview of hemodynamic parameters, and review of anticoagulants used in CRRT. The facilitator at this station was a critical care dialysis nurse. Students were required to access a patient record in Epic, renally adjust the patient's antibiotic regimen while on CRRT, and provide references to support the dosage adjustments.

The third station required students to access a patient chart through Allscripts and evaluate the medication list of a patient with end stage renal disease on hemodialysis to determine whether the medication regimen was appropriate based on presentation and laboratory examinations. After preparing recommendations as a group, one student verbally presented the patient case with recommendations to a preceptor in Situation, Background, Assessment, Recommendation (SBAR) format. A rubric, which has been consistently used during class, was utilized to evaluate the verbal presentations and provide feedback (Table 3 ).

A worksheet was used to evaluate accuracy of clinical recommendations and associated references in the first two stations. The SBAR rubric was used for the third station (Table 3). Since there is no validated assessment tool related to renal replacement therapies for pharmacy students, a pre- and post-simulation assessment was developed and composed of five questions. The faculty who taught the renal content created the questions, which were peer reviewed by other faculty members. Questions matched the simulation learning objectives and assessed the teaching points that were reinforced throughout the simulation (Table 1). The pre- and post-simulation assessments were administered through Canvas (Salt Lake City, UT) directly before and after the simulation. Students received credit for the simulation and for completing the assessments. Assessment questions remained the same pre- and post- simulation to ensure that knowledge obtained was from participation in the simulation.

The primary outcome was the difference in overall scores before and after the simulation. Secondary outcomes included the difference in overall scores for individual questions, overall differences between Cohort 1 (class of 2016) and Cohort 2 (class of 2017) prior to the simulation, and overall differences of each class before

Table 1. Renal Replacement Simulation Learning Objectives

\begin{tabular}{l}
\hline Station \\
$\begin{array}{l}\text { Formulate a pharmacotherapeutic plan for a patient on peritoneal dialysis with peritonitis, including doses and } \\
\text { monitoring parameters; } \\
\text { Describe the components of a peritoneal dialysis order set in an EMR system. }\end{array}$ \\
Gather, interpret, evaluate, and summarize drug information from primary, secondary, and tertiary literature and \\
communicate the results in a verbal or written manner appropriate to the requesting party; \\
Describe the dialysate solution composition. \\
Assess confidence level using EMRs during a simulation; \\
Verbally communicate a clear and concise evidence-based, patient-specific therapeutic plan in the form of an SBAR \\
for a hemodialysis patient.
\end{tabular}

Abbreviations: $\mathrm{EMR}=$ electronic medical record; SBAR = Situation, Background, Assessment, Recommendation 


\section{American Journal of Pharmaceutical Education 2019; 83 (2) Article 6519.}

and after the simulation. Pre- and post-simulation assessments were matched per student. The paired $t$-test was used to assess the change in overall performance on the assessment. The difference in overall scores for individual questions was assessed using the Cochrane $\mathrm{Q}$ test. The overall differences between the two classes prior to the simulation were assessed using the student's $t$-test. The differences of each class before and after the simulation were assessed using the paired $t$-test. $P$ values $<.05$ were statistically significant. Data was analyzed using the Real Statistics Resource Pack software, Version 4.1 (Real Statistics Using Excel, San Antonio, TX). ${ }^{19}$ Student perceptions of the simulation were garnered during the debrief session and from course evaluations. The study was determined to be exempt as non-human subject research by the Institutional Review Board at the University of South Florida.

\section{RESULTS}

There were 174 students who completed the simulation over the course of two years. Sixty-three students from the Cohort 1 and 111students from Cohort 2 completed the simulation, which is representative of the full class size (Table 2). For the primary outcome related to the difference in overall scores before and after the simulation, the average pre-simulation score was $55 \%$, while the average post-simulation score was $74 \%$. This difference was found to be statistically significant with a $p<.001$. For secondary outcomes, a significant overall difference was observed between questions related to indication for RRT, type of dialysis for hemodynamic instability, and agents to maintain circuit patency, $p<.001$ for each question. For secondary outcomes regarding interclass differences at baseline, the average score was $45 \%$ for Cohort 1 and $60.4 \%$ for Cohort $2, p<.001$. Similarly, significant inter-class differences were observed for questions related to indication for RRT and agents to maintain circuit patency, $p<.001$. In addition, there was a significant change in pre- and post-simulation assessment scores for each cohort. For Cohort 1, assessment scores increased from $45 \%$ to $72 \%, p<.001$. For Cohort 2 , assessment scores increased from $60 \%$ to $74 \%, p<.001$.

Students expressed satisfaction with the RRT simulation during the debrief sessions and course evaluations. Generally, students appreciated the opportunity to review and apply renal concepts later in the curriculum to review key concepts and enhance their clinical competence in this area. Furthermore, students enjoyed learning directly from the clinical pharmacy specialist and critical care nurse.

Table 2. Knowledge Assessment Before and After Participation in RRT Simulation Session

\begin{tabular}{|c|c|c|c|c|c|c|}
\hline & \multirow[b]{2}{*}{$\begin{array}{l}\text { Student } \\
\text { Response }\end{array}$} & \multicolumn{2}{|c|}{$\begin{array}{c}\text { Cohort } 1 \\
\mathrm{~N}=63\end{array}$} & \multicolumn{2}{|c|}{$\begin{array}{c}\text { Cohort } 2 \\
\mathrm{~N}=111\end{array}$} & \multirow[b]{2}{*}{$p$ value } \\
\hline & & $\begin{array}{c}\text { Pre-test } \\
\text { Score } \\
\text { Frequencies } \\
\text { n (\%) } \\
\end{array}$ & $\begin{array}{c}\text { Post-test } \\
\text { Score } \\
\text { Frequencies } \\
\text { n (\%) } \\
\end{array}$ & $\begin{array}{l}\text { Pre-test } \\
\text { Score } \\
\text { Frequencies } \\
\text { n (\%) } \\
\end{array}$ & $\begin{array}{l}\text { Post-test } \\
\text { Score } \\
\text { Frequencies } \\
\text { n (\%) } \\
\end{array}$ & \\
\hline \multirow{2}{*}{$\begin{array}{l}\text { An acronym for renal replacement therapy } \\
\text { indications is AEIOU. What do these } \\
\text { letters stand for? }\end{array}$} & I & $60(95)$ & $39(62)$ & $64(58)$ & $48(43)$ & \multirow[t]{2}{*}{$<.001$} \\
\hline & $\mathrm{C}$ & $3(5)$ & $24(38)$ & $47(42)$ & $63(57)$ & \\
\hline \multirow{2}{*}{$\begin{array}{l}\text { True/False: Patients with hemodynamic } \\
\text { instability may benefit from intermittent } \\
\text { hemodialysis rather than CRRT. }\end{array}$} & I & $39(62)$ & $22(35)$ & $55(49)$ & $30(27)$ & \multirow[t]{2}{*}{$<.001$} \\
\hline & $\mathrm{C}$ & $24(38)$ & $41(65)$ & $56(51)$ & $81(73)$ & \\
\hline \multirow{4}{*}{$\begin{array}{l}\text { Dialysate solutions may contain which of } \\
\text { the following? Select all that apply. }\end{array}$} & I & 0 & 0 & 0 & 0 & \multirow[t]{4}{*}{.41} \\
\hline & $\mathrm{PC}^{\mathrm{a}}$ & 0 & $2(3)$ & $1(1)$ & $4(4)$ & \\
\hline & $\mathrm{PC}^{\mathrm{b}}$ & $33(52)$ & $22(35)$ & $50(45)$ & $30(27)$ & \\
\hline & C & $30(48)$ & $39(62)$ & $60(42)$ & 77 (69) & \\
\hline \multirow{3}{*}{$\begin{array}{l}\text { Maintaining the patency of HD circuits is } \\
\text { achieved using which agents? Select all } \\
\text { that apply. }\end{array}$} & I & $46(73)$ & $3(5)$ & $57(54)$ & $26(23)$ & \multirow[t]{3}{*}{$<.001$} \\
\hline & $\mathrm{PC}^{\mathrm{c}}$ & $13(21)$ & $16(25)$ & $37(33)$ & $41(37)$ & \\
\hline & $\mathrm{C}$ & $4(6)$ & $44(70)$ & $17(15)$ & $44(40)$ & \\
\hline \multirow{4}{*}{$\begin{array}{l}\text { Drug dosing adjustments in renal replacement } \\
\text { therapy include modifications of which of } \\
\text { the following? Select all that apply. }\end{array}$} & I & 0 & 0 & 0 & 0 & \multirow[t]{4}{*}{.34} \\
\hline & $\mathrm{PC}^{\mathrm{a}}$ & $2(3)$ & $3(5)$ & $1(1)$ & $2(1)$ & \\
\hline & $\mathrm{PC}^{\mathrm{b}}$ & $25(40)$ & $13(21)$ & $31(28)$ & 19 (17) & \\
\hline & $\mathrm{C}$ & $36(57)$ & $47(75)$ & 79 (71) & $90(81)$ & \\
\hline
\end{tabular}

$\mathrm{I}=$ incorrect response; $\mathrm{C}=$ correct response; $\mathrm{PC}^{\mathrm{a}}=1$ out of 3 correct response; $\mathrm{PC}=2$ out of 3 correct responses; $\mathrm{PC}^{\mathrm{b}}=1$ out of 2 correct response; $\mathrm{AEIOU}=$ acidosis, electrolytes, intoxications, overload, uremia; $\mathrm{CRRT}=$ continuous renal replacement therapy; $\mathrm{HD}=$ hemodialysis 


\section{American Journal of Pharmaceutical Education 2019; 83 (2) Article 6519.}

Table 3. Situation, Background, Assessment, Recommendation (SBAR) Rubric

\begin{tabular}{|c|c|c|c|}
\hline$\overline{\text { Component }}$ & 2: Satisfactory & 1: Unsatisfactory & 0: Not Addressed \\
\hline Situation & Correctly identifies situation & Misses key points & Situation not discussed \\
\hline Background & $\begin{array}{l}\text { Correctly identifies pertinent } \\
\text { background }\end{array}$ & Misses key components of background & Background not discussed \\
\hline Assessment & Correctly identifies assessment & Misses key components of assessment & Assessment not discussed \\
\hline Recommendations & $\begin{array}{l}\text { Accurately and completely develops } \\
\text { recommendations }\end{array}$ & $\begin{array}{l}\text { Misses key components of } \\
\text { recommendations }\end{array}$ & $\begin{array}{l}\text { Recommendations not } \\
\text { discussed }\end{array}$ \\
\hline Duration & $\begin{array}{l}\text { Completes SBAR during } \\
\text { recommended time allotted }\end{array}$ & SBAR too long/short for allotted time & $\mathrm{N} / \mathrm{A}$ \\
\hline $\begin{array}{l}\text { Vocabulary \& } \\
\text { Eye Contact }\end{array}$ & $\begin{array}{l}\text { Uses vocabulary and phraseology } \\
\text { appropriate for health care } \\
\text { professionals with appropriate } \\
\text { eye contact }\end{array}$ & $\begin{array}{l}\text { Uses inappropriate vocabulary and } \\
\text { phraseology for health care } \\
\text { professionals and/or } \\
\text { inappropriate eye contact }\end{array}$ & $\mathrm{N} / \mathrm{A}$ \\
\hline
\end{tabular}

Evaluators were also asked to provide comments for each of the areas

\section{DISCUSSION}

Although pharmacists are not directly involved with initiation and implementation of specific renal replacement modalities, they play an integral role across a patient's spectrum of care. ${ }^{20}$ Opportunities arise in the primary care setting for patients with CKD regarding medication management of $\mathrm{CKD}$ and other comorbid conditions in order to prevent disease progression. ${ }^{21}$ In acute care settings, pharmacists must be vigilant in caring for patients on RRT for optimal drug dosing and any acute changes requiring dosing adjustments. Such clinical pharmacy services lead to improved patient care, although clear outcomes attributed directly to pharmacist involvement have not been quantified in the literature. ${ }^{22}$ For these reasons, it is imperative for students to appreciate the breadth of clinical management for these patients.

This simulation allowed for reinforcement of content related to CKD and RRT, which were taught in the previous years of the curriculum. It also offered students an opportunity to apply their knowledge through patient cases and associated discussions with content area experts from an affiliated teaching hospital. The objectives of this activity aligned with several ACPE standards. ${ }^{3}$ To date, pharmacy education literature is limited in depicting live simulations related to $\mathrm{CKD}$ and renal replacement modalities.

Results from the pre- and post-simulation assessments demonstrate an overall increase in knowledge after the simulation. Further evaluation of each question showed a statistically significant improvement of knowledge on questions 1,2 , and 4, which are related to indications for RRT, patient-specific selection of RRT modalities, and appropriate anticoagulation for each modality, respectively. This is representative of the key discussion points iterated during the simulation, which were not often emphasized in other cases and activities. For example, students have encountered multiple renal drug dose adjustments in cases and drug information questions within other courses. However, the content of these specific three questions did not often arise elsewhere in the curriculum. For this reason, results can be directly attributed to the RRT simulation. Since students completed the pre- and post-simulation knowledge assessments individually and on the same day as the simulation, authors do not anticipate confounders to the results.

There was no demographic baseline statistical analysis conducted to examine the differences between Cohort 1 and 2, which is a limitation of this study. The secondary outcome related to inter-class differences depicted an increase in baseline knowledge prior to the simulation. Originally for Cohort 1 , the didactic lecture component was combined with the simulation experience on the same day. Students provided feedback that they would have benefitted had the lecture been separated from the simulation activity to allow time to study the material. For this reason, faculty separated the components by one week to allow more time for students to review the materials prior to participating in the simulation. This may explain the difference in baseline knowledge between the two cohorts of classes.

One of the strengths of this simulation is related to vertical and horizontal alignment to enhance student knowledge from the renal module as well as integration of other skills such as utilization of drug information resources and pharmaceutical calculations. Utilization of simulation is one of the strengths of this activity, 


\section{American Journal of Pharmaceutical Education 2019; 83 (2) Article 6519.}

which encompassed the spectrum of renal replacement modalities. Students had been introduced to these concepts in previous years, but the activity allowed for demonstration and application of specific, real-life scenarios related to RRT and encouraged critical thinking skills to evaluate resources related to drug dosing. Inclusion of the clinical pharmacy specialist and critical care dialysis nurse added to the depth of content delivery, allowing students to ask specific questions and network with content area specialists. Furthermore, involvement of the nurse specialist has reinforced the importance of interprofessional practice, especially in the care of patients requiring high acuity care.

The assessment questions were not validated, which may limit generalizability of the results. Another limitation of the activity includes time constraints for students to complete the tasks at each station. Student feedback included the need for more time to complete a thorough SBAR that addressed all aspects of the patient's CKD. Additionally, students expressed a desire to complete the simulation individually, rather than in their academic groups, to strengthen their abilities. Although this would be beneficial to encourage individual learning, it poses the challenge of having all students complete the simulation during allotted class time.

Future considerations involve increasing the time in each station for students to complete the activities and use the expertise of the specialists during the simulation. Additionally, the simulation may be expanded for an interprofessional component, especially with medical students (to include hemodynamic parameters and diuresis) and nursing students (to include IV access sites, etc.). Such a simulation would also be ideal to depict a transitions of care model that follows a patient with acute or chronic kidney disease throughout the continuum of care.

\section{CONCLUSION}

Simulation can be used effectively to reinforce and teach renal pharmacotherapy content learned didactically. This simulation encompassed various aspects of RRT modalities that often have limited coverage within pharmacy curricula. Curricular alignment between the pharmacotherapeutics and pharmaceutical skills courses allowed opportunities for critical thinking and application of clinical concepts, which aligns with both the ACPE Standards 2016 and the 2013 CAPE Outcomes. ${ }^{3,4}$

\section{REFERENCES}

1. National Kidney Foundation. KDIGO 2012 clinical practice guidelines for the evaluation and management of chronic kidney disease. Kidney Int Supple. 2013;3(1). http://www.kdigo.org/ clinical_practice_guidelines/pdf/CKD/KDIGO_2012_CKD_GL.pdf. Accessed May 12, 2017.
2. National Kidney Foundation. KDIGO clinical practice guidelines for acute kidney injury. Kidney Int Suppl. 2012;2(1). http://www. kdigo.org/clinical_practice_guidelines/pdf/KDIGO $\% 20 \mathrm{AKI} \%$ 20Guideline.pdf. Accessed May 12, 2017.

3. Accreditation Council for Pharmacy Education. Guidance for the accreditation standards and key elements for the professional program in pharmacy leading to the doctor of pharmacy degree. Standards 2016. https://www.acpe-accredit. org/pdf/GuidanceforStandards2016FINAL.pdf. Accessed May 12, 2017.

4. Center for the Advancement of Pharmacy Education. CAPE Educational Outcomes. 2013. https:/www.aacp.org/sites/default/ files/2017-10/CAPEoutcomes2013\%20\%281\%29.pdf. Accessed May 12, 2017.

5. American Society of Health System Pharmacists. Pharmacists' competency assessment library. https://www.ashp.org/Productsand-Services/Institutional-Subscriptions/For-Institutions/ Pharmacists-Competency-Assessment-Library. Accessed May 12, 2017.

6. Hudson D, Dunbar-Reid K, Sinclair PM. The incorporation of high fidelity simulation training into hemodialysis nursing education: part 2-a pictorial guide to modifying a high fidelity simulator for use in simulating hemodialysis. Nephrol Nurs $J$. 2012;39(2):119-123.

7. Dunbar-Reid K, Sinclair PM, Hudson D. Advancing renal education: hybrid simulation, using simulated patient to enhance realism in haemodialysis education. J Ren Care. 2015;41(2): 134-139.

8. Cook DA, Hatala R, Brydges R, et al. Technology-enhanced simulation for health professions education: a systematic review and meta-analysis. JAMA. 2011;306(9):978-88.

9. Thompson Bastian ML, Cook AM, Flannery AH. Use of simulation training to prepare pharmacy residents for medical emergencies. Am J Health Syst Pharm.

2017;74(6):424-429.

10. Kostoff M, Burkhardt C, Winter A, Shrader S. An

interprofessional simulation using the SBAR communication tool. Am J Pharm Educ. 2016;80(9):Article 157.

11. Craven MG, Benner K, Beall J, et al. Knowledge gain of pharmacy students and pharmacist comparing simulation versus traditional learning methodology. $J$ Pediatr Pharmacol Ther. 2016;21(6):476-485.

12. Maxwell WD, Mohorn PL, Haney JS, et al. Impact of an advanced cardiac life support simulation laboratory experience on pharmacy student confidence and knowledge. Am J Pharm Educ. 2016;80(8):Article 140.

13. Katja S, Grant DT. A model for self-directed problem-based learning for renal therapeutics. Am J Pharm Educ. 2010;74(9):Article 173.

14. Pierce R, Fox J. Vodcasts and active-learning experiences in a "flipped classroom" model of a pharmacotherapy module. Am J Pharm Educ. 2012;76(10):Article 196.

15. Chisholm, MA. A renal transplantation advanced pharmacy practice experience. Am J Pharm Educ. 2006;70(1): Article 70.

16. Strohfeldt K and DT Grant. A model for self-directed problembased learning for renal therapeutics. Am J Pharm Educ. 2010;74(9): Article 196.

17. Benedict N, K Schonder. Patient simulation software to augment an advanced pharmaceutics course. Am J Pharm Educ. 2011;75(2): Article 21. 


\section{American Journal of Pharmaceutical Education 2019; 83 (2) Article 6519.}

18. Vanderbilt University Center for Teaching. Bloom's Taxonomy. https://cft.vanderbilt.edu/guides-sub-pages/blooms-taxonomy/. Accessed May 6, 2017.

19. Zaiontz C. 2013. Real statistics using Excel. [Computer software]. http://www.real-statistics.com/free-download/. Accessed May 6, 2017.

20. St. Peter W. Introduction: chronic kidney disease: a burgeoning health epidemic. JMCP. 2007;13(9 Suppl D).S2-S5.
21. Zillich AJ, Saseen JJ, Dehart RM, et al. Caring for patients with chronic kidney disease: a joint opinion of the ambulatory care and the nephrology practice and research networks of the American College of Clinical Pharmacists. Pharmacotherapy. 2005;25(1):123-143.

22. Stemer G, Lemmens-Gruber R. Clinical pharmacy activities in chronic kidney disease and end stage renal disease patients: a systematic literature review. BMC Nephrol. 2011;12:35. 